\title{
Older Adult-Centred Design
}

\author{
Mona Afifi ${ }^{1,4}$, Mohamed Al-Hussein ${ }^{2}$ and Ahmed Bouferguene ${ }^{3}$ \\ ${ }^{1}$ PhD candidate, Department of Civil Engineering, Hole School of Construction Engineering, \\ University of Alberta \\ 2 Professor, Department of Civil Engineering, Hole School of Construction Engineering, \\ University of Alberta \\ ${ }^{3}$ Associate Professor, Department of Civil Engineering, Hole School of Construction \\ Engineering, University of Alberta \\ ${ }^{4}$ Corresponding author's e-mail: mkafifi@ualberta.ca
}

\begin{abstract}
A poorly designed home environment is likely to cause falling for older adults. By employing the concept of older adult-centred design, home design that reduces the risk of falls for older adults can be achieved. This approach focuses on meeting specific human needs and enabling individuals to experience improved functionality within the living space. This paper presents an evidencebased analysis of bathroom design from the perspective of reducing the risk of falling for older adults. The methodology is divided into three stages: (1) evidence-based review of bathroom design; (2) cohesive analysis of evidence-based studies; and (3) definition of best practice for older adult-centred design. The outcome of this paper is an evidence-based approach to older adultcentred design that is associated with the minimum risk of falling.
\end{abstract}

\section{KEYWORDS}

Older adults, Evidence-based, fall, adult-centred design, human-centred design

\section{INTRODUCTION}

In the next 25 years, the Canadian population of older adults aged 65 years and over is expected to double to approximately 10.4 million by 2036, forming one of the largest demographic waves in Canadian history. The safety of an aging population is an increasing concern that needs to be addressed. One in three older adults is expected to experience at least one fall per year in the home environment (Donald and Bulpitt 1999; Elliott et al. 2009; Gillespie et al. 2003; PHAC 2014; Scott et al. 2005). Most falls that take place in the home lead to injuries and hospitalization (PHAC 2014). In addition, $10 \%$ of these injures have been classified as serious injuries such as hip fractures and head injuries (O'Loughlin et al. 1993; Tinetti et al. 1995; Tinetti et al. 1988). Also, older adults who have experienced a fall are subject to develop social withdrawal, fear of falling, and activity restriction due to falling (Kannus et al. 2005; Nevitt et al. 1991; Rogers et al. 2004; Tinetti and Williams 1998; Vellas et al. 1997). Some home spaces, such as the bathroom, have been associated with a greater risk of falling for older adults (Devito et al. 1988; Nevitt et al. 1989). Evidence-based studies have reported difficulty for older adults to perform Activities of Daily Living (ADL); this refers to cases in which a simple task, such as standing up from the toilet or stepping out of the shower, found to be difficult for an older adult to perform (Aminzadeh et al. 2000; Buchman et al. 2014). 
Human-centred design is an approach to meet human needs and enable individuals to better function within a given space. Lawton and Nahemow (1973) have presented a framework to model the reciprocal relationship between users, (in this case, older adults), and the environment (Lawton M. P. 1973). In the 1980s, the term universal design or life span design was used to refer to an approach to designing the built environment to function for different ages and abilities. Norman and Draper (1986) first introduced this user-centric design as a new practice through human computer integration (Norman and Draper 1986). Human-centric design has been acknowledged by International Organization for Standardization (ISO) 13407 (1999) standards as a process for system development. Human-centred design, in its most recent definition, includes optimizing the physical design of the surrounding environment in order to meet the needs and abilities of users. In 2012, three major design paradigms have been identified by Giacomin (2012): (1) technologydriven design that focuses on technology implementation; (2) sustainability-driven design that focuses on human ecological footprint and impact on the surrounding environment; and (3) humancentred design that focuses on satisfying human needs (Giacomin 2012).

This paper presents the concept of older adult-centred design. Designing a home for older adults associated with the minimum risk of falls can be achieved through the application of this concept, which is an approach branching from the concept of human-centred design in order to meet the needs of older adults as a specific group. The concept of older adult-centred design enables individuals to better function within various home spaces, such as the bathroom. This older adultcentred design concept is proposed through an evidence-based analysis that is implemented in bathroom design from the perspective of reducing the risk of falling for older adults. The methodology is divided into three stages: (1) evidence-based review of bathroom design; (2) cohesive analysis of collected evidence-based studies; and (3) definition of best practice for older adult-centred design (see Figure 1).

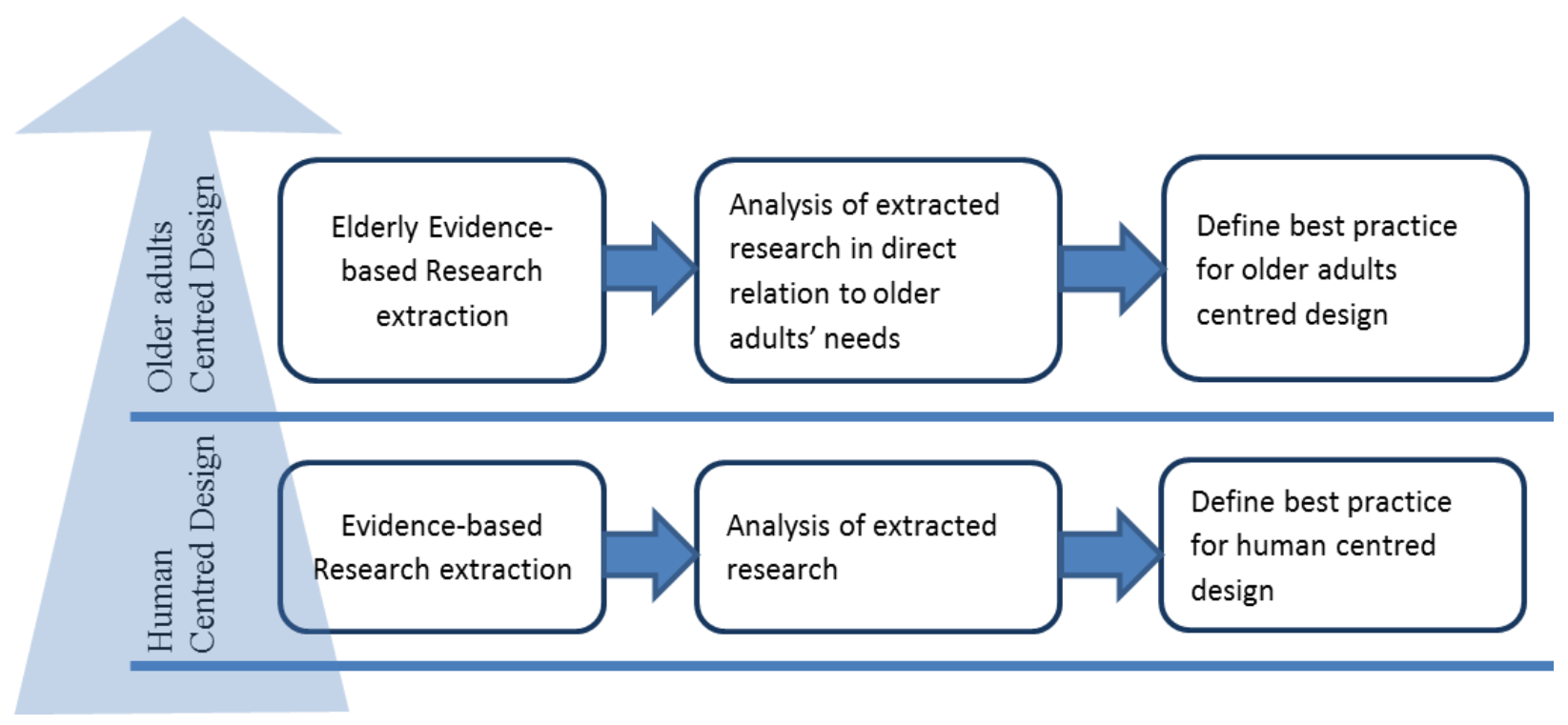

Figure 1. Research methodology for older adult-centred design in relation to human-centred design 
The proposed research methodology represents a human-centred design implemented for a specific group of older adults, which can be broadened to include different groups of people sharing similar needs, such as children in schools, workers in factories, and patients in hospitals. Since the centre of all approaches is human need, the concept of human-centred design can be studied from multiple perspectives, such as ergonomics, physiology, and safety (Giacomin 2012). In this paper, older adults' safety in relation to risk of falling is the main concern.

\section{BATHROOM DESIGN}

The toilet and bathtub are two bathroom design elements featured in most home bathrooms (Aminzadeh et al. 2000; Parrott et al. 2013). This paper identifies evidence-based research with respect to these two bathroom design elements, with older adults being the center of the process as evidence-based papers are presented to satisfy older adults' group needs. Based on the analysis of evidence-based studies, best practice is formulated for older adult-centred design. This research adopts an evidence-based study analysis approach, based on applying the optimal available research results that is been extracted from evidence-based practice methods such as randomized control trials studies. This strategy is in line with the assertion of Youngblut (2001) study that evidence-based studies are likely to result in the most desirable outcome for users (Youngblut and Brooten 2001).

\section{Bathroom Toilet Design}

Toilet height needs to be adjusted to facilitate sit-to-stand activity for older adults. Clarke (1984) has shown that many older adults lack the ability to stand from a seated position (Clarke et al. 1984). Trying to stand from a seated position may cause a shift in center of mass, which can cause an older adult to fall (Campbell et al. 1989; Nevitt et al. 1989; Tinetti et al. 1986). Capezuti (2008) has found that toilet height needs to be $100 \%$ to $120 \%$ of the older adults' lower leg length in order to safely perform sit-to-stand action. In addition, some additional devices such as toilet grab-bars must be installed to facilitate both sitting down and standing up from the toilet (Sanford et al. 1995).

Based on Sanford's (1995) study, the optimal toilet grab-bar system requires two components: (A) one bar 1,220 $\mathrm{mm}$ in length, installed diagonally at a $45^{\circ}$ angle, $500 \mathrm{~mm}$ distance from the end of the toilet; and (B) another bar $500 \mathrm{~mm}$ in length, installed horizontally, $300 \mathrm{~mm}$ distance from the end of the toilet (see Figure 2). The toilet grab-bar must have the appropriate surface texture (not too smooth and not too rough) in order to be safe for the grasping hand (Haslam and Stubbs 2006; Maki 1988; Templer 1992); a grab-bar that is too smooth or too rough may cause the grasping hand to slide, which can produce a sudden action of trying to re-grasp the grab-bar, thereby increasing the likelihood of a fall. Additionally, some falls may result from a larger or smaller diameter of the toilet grab-bar (Maki 1988). Maki (1988) identified the optimal grab-bar diameter to range from $32 \mathrm{~mm}$ to $51 \mathrm{~mm}$. 


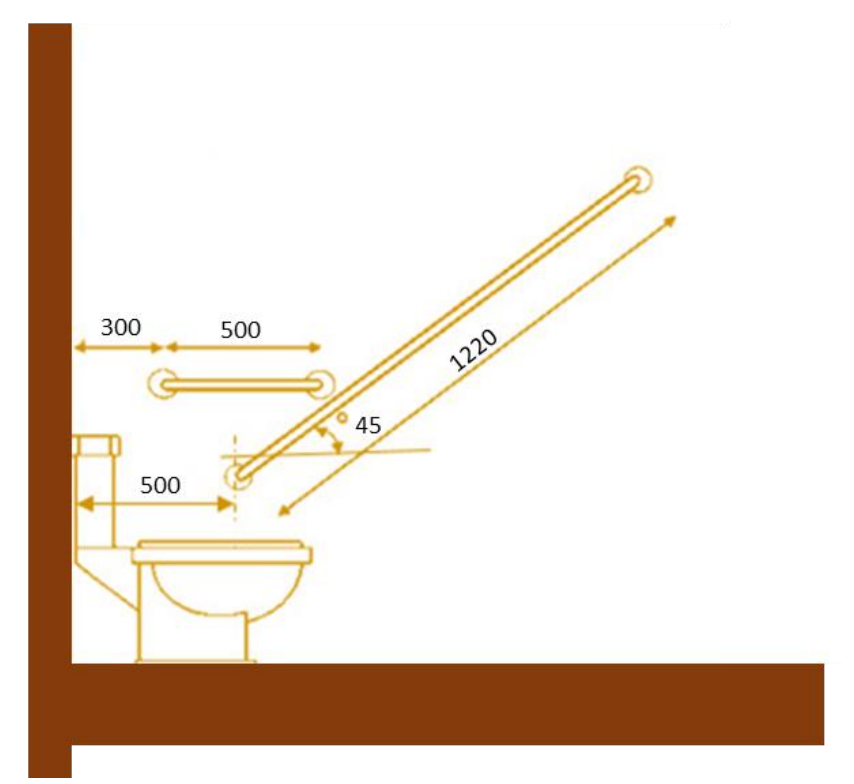

Figure 2. Toilet grab-bar optimal dimension (all dimensions in millimeters).

\section{Bathtub design}

In order to facilitate the movement of (1) getting in and out of the bathtub, and (2) getting up from and laying down in the bathtub, Sveistrup (2006) has examined different grab-bar sets. Based on this study, the optimal grab-bar set associated with the minimum risk of falling and with best facilitating getting in and out of the bathtub is illustrated in Figure 3: the bar is 1,200 mm in length, is vertically installed, and satisfies distance of $180 \mathrm{~mm}$ to $280 \mathrm{~mm}$ from the bottom of the grabbar to the top of the tub rim (Sveistrup et al. 2006). As illustrated in Figure 4, the optimal grab-bar set associated with the minimum risk of falling and that best facilitates getting up from and laying down in the bathtub has been found by Sveistrup (2006) to be either: (A) 1,200 mm in length, horizontally installed within $180 \mathrm{~mm}$ to $280 \mathrm{~mm}$ distance from the top of the tub rim to the bottom of the grab-bar, and installed on the back wall of the bathtub; or (B) $600 \mathrm{~mm}$ in length, installed diagonally at a $45^{\circ}$ angle on the back wall of the bathtub, and installed $300 \mathrm{~mm}$ distance from the side wall and $150 \mathrm{~mm}$ distance from the top of the bathtub rim.

Bathtub surface texture and diameter specifications should be, as with the toilet design specifications described above, not too rough and not too smooth, and the optimal diameter range is from $32 \mathrm{~mm}$ to 51sdddd $\mathrm{mm}$ (Maki 1988). Slippery bathtub floors, in addition to unfixed bathroom mats, have been associated with a high risk of falling for older adults (Clemson and Martin 1996; Sveistrup et al. 2006). Therefore, the optimal scenario for safe gait movement within the bathtub is to have a non-slip bathtub floor surface with a well fixed non-slip bathtub mat, if existed (Clemson and Martin 1996; Sveistrup et al. 2006). 


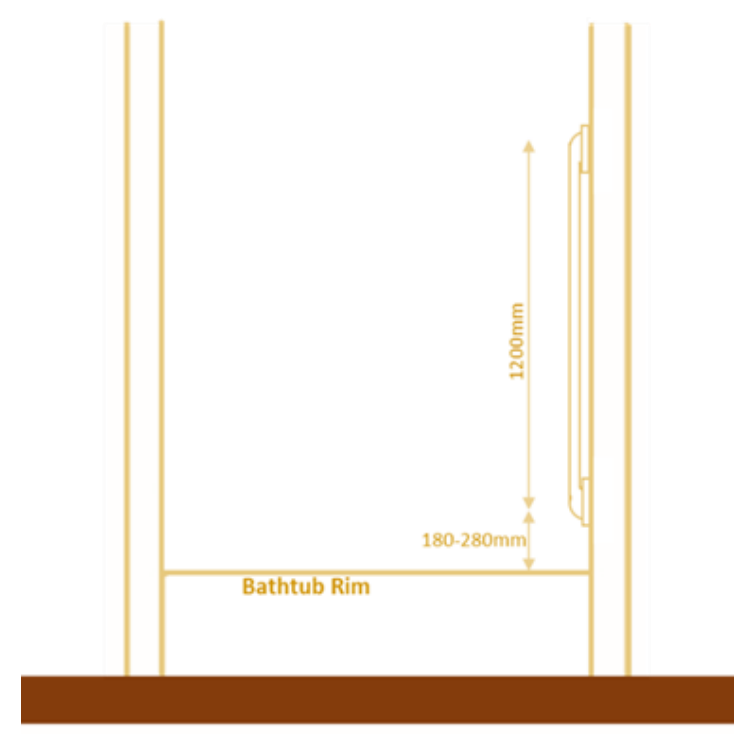

Figure 3. Optimal bathtub grab-bar configuration for side wall installation (all dimensions in millimetres).
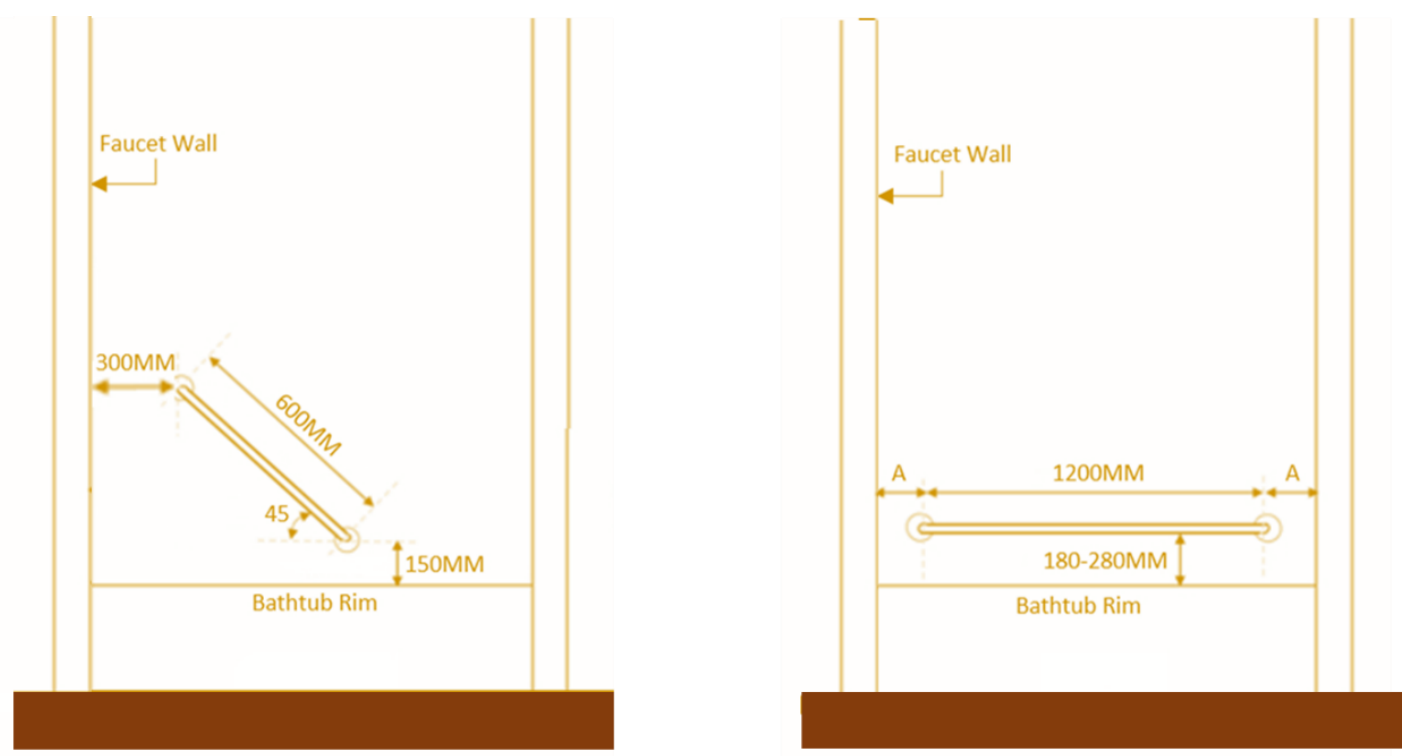

Figure 4. Optimal bathtub grab-bar configuration for back wall installation.

\section{CONCLUSION}

The concept of older adult-centred design is proposed in this paper through an evidence-based analysis that is implemented in bathroom design, as an example of a home space, and from the perspective of reducing the risk of falling for older adults. The authors believe in multi-disciplinary approach to address factors in relation to falls, such as optimal home environmental design to reduce the risk of falling for older adults. This paper proposes a framework to improve the home environment with older adults being the center of the process. This concept is implemented through selecting evidence-based studies that is developed for older adults participants aged 65 years and 
over. With a focus on older adults being the center of process, best practice for older adults that is associated with the minimum risk reduction is proposed in this research, which identifies an implemented methodology to older adult- centered design.

\section{REFERENCES}

Aminzadeh, F., Edwards, N., Lockett, D., and Nair, R. C. (2000). "Utilization of bathroom safety devices, patterns of bathing and toileting, and bathroom falls in a sample of community living older adults." Technology and Disability, 13(1), 95-103.

Buchman, A. S., Wilson, R. S., Yu, L., James, B. D., Boyle, P. A., and Bennett, D. A. (2014). "Total daily activity declines more rapidly with increasing age in older adults." Archives of Gerontology and Geriatrics, 58(1), 74-79.

Campbell, A. J., Borrie, M. J., and Spears, G. F. (1989). "Risk factors for falls in a communitybased prospective study of people 70 years and older." J Gerontol, 44(4), M112-117.

Clarke, M., Clarke, S., Odell, A., and Jagger, C. (1984). "The elderly at home: health and social status." Health Trends, 16, 3-7.

Clemson, L., and Martin, R. (1996). "Usage and effectiveness of rails, bathing and toileting AIDS." Occup Ther Health Care, 10(1), 41-59.

Devito, C. A., Lambert, D. A., Sattin, R. W., Bacchelli, S., Ros, A., and Rodriguez, J. G. (1988). "Fall injuries among the elderly. Community-based surveillance." J. Am. Geriatr. Soc., 36(11), 1029-1035.

Donald, L. P., and Bulpitt, C. J. (1999). "The Prognosis of Falls in Elderly People Living at Home." Age and Ageing, 28, 121 - 125.

Elliott, S., Painter, J., and Hudson, S. (2009). "Living alone and fall risk factors in communitydwelling middle age and older adults." Journal of community health, 34(4), 301-310.

Giacomin, J. (2012). "What is Human Centred Design?." Human Centred Design Institute, Brunel University Uxbridge, Middlesex, United Kingdom

Gillespie, L. D., Gillespie, W. J., Robertson, M. C., Lamb, S. E., Cumming, R. G., and Rowe, B. H. (2003). "Interventions for preventing falls in elderly people." Cochrane Database Syst Rev, 4.

Haslam, R., and Stubbs, D. (2006). Understanding and Preventing Falls, Taylor \& Francis, Boca Raton, Fla. ; London.

Kannus, P., Sievanen, H., Palvanen, M., Jarvinen, T., and Parkkari, J. (2005). "Prevention of falls and consequent injuries in elderly people." Lancet, 366(9500), 1885-1893.

Lawton M. P., N. L. (1973). The psychology of adult development and aging (Ecology and the Aging Process), American Psychological Association, Washington.

Maki, B. E. (1988). Influence of Handrail Shape, Size and Surface Texture on the Ability of Young and Elderly Users to Generate Stabilizing Forces and Moment, Editiorial Office, Division of Electrical Engineering,National Research Council of Canada, Ottawa.

Nevitt, M. C., Cummings, S. R., and Hudes, E. S. (1991). "Risk factors for injurious falls: a prospective study." J Gerontol, 46(5), M164-170.

Nevitt, M. C., Cummings, S. R., Kidd, S., and Black, D. (1989). "Risk factors for recurrent nonsyncopal falls. A prospective study." Jama, 261(18), 2663-2668.

Norman, D. A., and Draper, S. W. (1986). User Centered System Design: A new perspective on Human-Computer Interaction, Lawrence Erlbaum \& Associates, Hillsdale, N.J. 
O'Loughlin, J. L., Robitaille, Y., Boivin, J. F., and Suissa, S. (1993). "Incidence of and risk factors for falls and injurious falls among the community-dwelling elderly." Am J Epidemiol, 137(3), 342-354.

Parrott, K. R., Beamish, J., Emmel, J., and Peterson, M. J. (2013). Bath planning : guidelines, codes, standards, Wiley, Hoboken, New Jersey.

PHAC (2014). "Public Health Agency of Canada, Seniors' Falls in Canada, Second Report."Ottawa.

Rogers, M. E., Rogers, N. L., Takeshima, N., and Islam, M. M. (2004). "Reducing the Risk for Falls in the Homes of Older Adults." Journal of Housing For the Elderly, 18(2), 29 - 39.

Sanford, J. A., Arch, M., and Megrew, M. B. (1995). "An evaluation of grab bars to meet the needs of elderly people." Assist Technol, 7(1), 36-47.

Scott, V., Pearce, M., and Pengelly, C. (2005). "Technical Report: Injury Resulting from Falls Among Canadians Age 65 and over (on the Analysis of Data from the Canadian Community Health Survey, Cycle 2.1, as Presented in: Report on Seniors' Falls in Canada)."Victoria, BC Public Health Agency of Canada.

Sveistrup, H., Lockett, D., Edwards, N., and Aminzadeh, F. (2006). "Evaluation of bath grab bar placement for older adults." Technology and Disability, 18(2), 45-55.

Templer, J. A. (1992). The Staircase: Studies of Hazards, Falls, and Safer Design, MIT Press, Cambridge, Mass.

Tinetti, M. E., Doucette, J., Claus, E., and Marottoli, R. (1995). "Risk factors for serious injury during falls by older persons in the community." J Am Geriatr Soc, 43(11), 1214-1221.

Tinetti, M. E., Speechley, M., and Ginter, S. F. (1988). "Risk factors for falls among elderly persons living in the community." N Engl J Med, 319(26), 1701-1707.

Tinetti, M. E., and Williams, C. S. (1998). "The effect of falls and fall injuries on functioning in community-dwelling older persons." J Gerontol A Biol Sci Med Sci, 53(2), M112-119.

Tinetti, M. E., Williams, T. F., and Mayewski, R. (1986). "Fall risk index for elderly patients based on number of chronic disabilities." Am J Med, 80(3), 429-434.

Vellas, B. J., Wayne, S. J., Romero, L. J., Baumgartner, R. N., and Garry, P. J. (1997). "Fear of Falling and Restriction of Mobility in Elderly Fallers." Age Ageing, 26(3), 189-193.

Youngblut, J. M., and Brooten, D. (2001). "Evidence-based nursing practice: why is it important?" AACN Clin Issues, 12(4), 468-476. 